\title{
PARANEOPLASTIC PALMO PLANTAR KERATODERMA: A CASE REPORT
}

T. V. Anoop ${ }^{1}$, K. Radhakrishnan², S. Ajayakumar³, S. Rajiv4, M. Revathy ${ }^{5}$

\section{HOW TO CITE THIS ARTICLE:}

T. V. Anoop, K. Radhakrishnan, S. Ajayakumar, S. Rajiv, M. Revathy. "Paraneoplastic Palmo Plantar Keratoderma: A Case Report". Journal of Evolution of Medical and Dental Sciences 2014; Vol. 3, Issue 32, August 04;

Page: 8800-8803, DOI: 10.14260/jemds/2014/3126

ABSTRACT: Palmoplantar keratodermas are a heterogeneous group of disorders characterized by hyperkeratosis of palms and soles. We report the case of a 65 year old male who presented with diffuse hyperkeratosis of palms and soles along with dystrophy and shedding of nails of six months duration. Investigations to detect an underlying malignancy were negative. He was treated symptomatically and kept under follow up. Three months later, he presented with generalized pruritus and hard jugulo digastric and axillary lymph nodes, which revealed metastatic deposits. Investigation failed to show the focus of malignancy and was given chemotherapy under "metastasis of unknown origin" category with which there was marked improvement of his cutaneous symptoms. KEYWORDS: Acquired Palmoplantar Keratoderma, Internal malignancy.

INTRODUCTION: Palmoplantar keratodermas are a heterogeneous group of disorders characterized by hyperkeratosis of palms and soles. ${ }^{1}$ They may be broadly classified into inherited and acquired. Based on the pattern of involvement, palmoplantar keratoderma may be classified into focal, punctuate and diffuse. Acquired PPK may be associated with psoriasis, lichen planus, Reiter's syndrome, pityriasis rubra pilaris, verrucae, fungal infections, keratoderma climactericum, contact dermatitis and also internal malignancy. ${ }^{2}$ Association may either be a paraneoplastic phenomenon or malignancy predisposition.

CASE REPORT: A 65years old male, chronic smoker and alcoholic, presented with diffuse thickening \& fissuring of palms and soles of 6months duration. He also had pruritic, scaly thickened lesion over knees of 3months duration. Examination revealed a moderately built and nourished individual with bilateral pitting pedal edema. Cutaneous examination showed hyperkeratosis and fissuring of palms and soles. Hyperkeratotic, scaly plaques with ill-defined borders of size $2 \times 1 \mathrm{~cm}$ were present over the knees. Auspitz sign was negative. All the fingers showed anonychiya. All systems were within normal limits.

A clinical differential diagnosis of acquired palmoplantar keratoderma (PPK) secondary to internal malignancy and palmoplantar psoriasis was made. Acquired PPK secondary to malignancy was considered due to the sudden onset of the condition and the old age of the patient. Complete haemogram was normal except for eosinophilia (10\%). Skin biopsy of the palm revealed epidermolytic hyperkeratosis, a few scattered apoptotic keratinocytes, mild pigment incontinence in the basal layer and perivascular inflammation in the upper dermis.

Investigations to rule out internal malignancy like chest X ray, upper GI endoscopy and colonoscopy were normal. Carcino embryonic antigen (CEA) and Prostate specific antigen (PSA) were normal but Alpha feto protein (AFP) was marginally elevated. Ultrasound abdomen revealed grade I prostatomegaly and hemangioma in right lobe of liver. He was treated symptomatically with antibiotics for the secondary infection, moisturizers and salicylic acid. 


\section{CASE REPORT}

3 months later, patient presented with generalized pruritus. Examination showed hard, discrete, enlarged jugulo digastric and axillary lymph nodes with restricted mobility on right side. He also had generalized xerosis, hyperkeratosis over the palms and soles, minimal lichenification over knees and anonychia. Clinical examinations of the other systems were normal. Lymph node biopsy showed metastatic deposits from poorly differentiated carcinoma of possibly nasopharyngeal origin.

Ear, nose and throat were normal. Computed Tomography (CT) of head, neck and thorax showed no focus of malignancy.

A revised diagnosis of acquired palmoplantar keratoderma secondary to metastatic carcinoma of undetected primary was made. The patient received chemotherapy with Gemcitabine and Carboplatin under the 'Metastasis of Unknown Origin' category with improvement of symptoms.

\section{Fig. 1: Diffuse hyperkeratosis of palms}

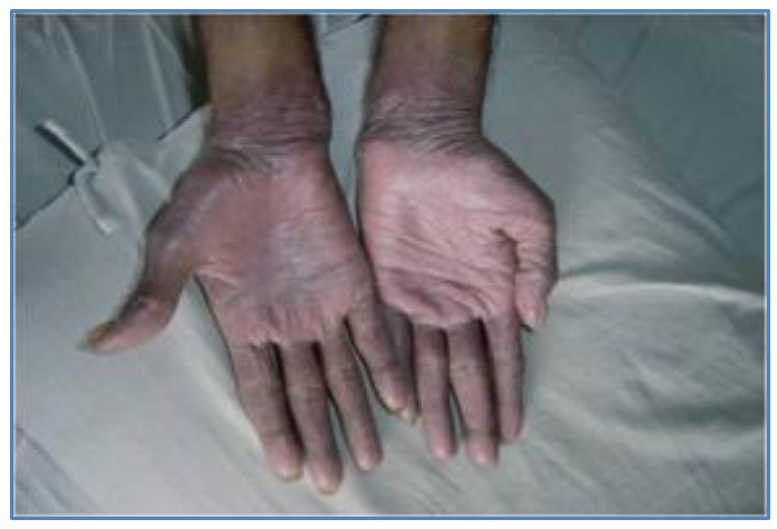

Fig. 1

Fig. 2: H \& E section of skin100x showing epidermolytic hyperkeratosis, apoptotic keratinocytes, pigmentary incontinence, mild perivascular inflammation.

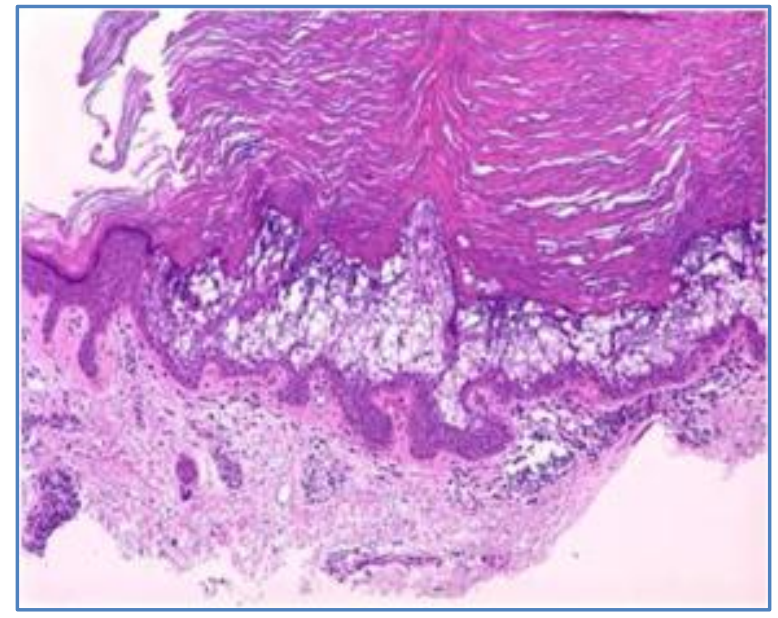

Fig. 2 
DISCUSSION: In 1880, Thost described the first case of diffuse hereditary palmoplantar keratoderma (PPK), which he considered as a form of ichthyosis. ${ }^{3}$ Three years later, Unna clearly separated this entity from the various ichthyoses. It is characterized by hyperkeratosis of palms and soles. ${ }^{4}$ They may be broadly classified into inherited and acquired.

Acquired PPK can occur due to various inflammatory and reactive dermatoses like chronic hand dermatitis, psoriasis, keratoderma blennorrhagica (Reiter syndrome), pityriasis rubra pilaris, lichen planus. Infections such as tinea pedis, crusted scabies, plantar wart, syphilis and leprosy can also cause PPK. ${ }^{5}$

Chronic arsenic exposure can result in multiple, irregular, warty keratotic lesions on the palms and soles. Onset of PPK may occur 10-30 years after ingestion of arsenic. Drug hypersensitivity may result from agents such as verapamil, quinacrine, etodolac, mepacrine, proguanil, mexiletine, methyldopa, lithium, venlafaxine, gold, fluorouracil, bleomycin, hydroxyurea, practolol and doxorubicin. ${ }^{5}$

Systemic diseases like myxedema, diabetes mellitus, chronic lymphedema and other circulatory disorders such as acrocyanosis and livedo reticularis have been associated with PPK. Diets lacking protein energy and vitamin deficiency have been implicated in PPK with associated fissuring.

Acute onset of PPK in the elderly age group should raise the possibility of association with internal malignancy. The association may be either be a paraneoplastic phenomenon or a manifestation of malignancy predisposition. Paraneoplastic dermatoses develop after the onset of malignancy and follow a parallel course, thereby allowing early diagnosis and treatment. Keratodermas have been associated with carcinomas of the oesophagus, lung, breast, stomach, pancreas, kidney, bladder and colon.

Bazex established an association between PPK and squamous cell carcinoma of head and neck and oesophagus. Acrokeratosis paraneoplastica of Bazex affects white men aged 40years and older. Howel-Evans syndrome or tylosis-esophageal cancer syndrome is a familial form of focal PPK associated with a high incidence of oesophageal carcinoma. ${ }^{6}$ Diffuse PPK is seen in association with carcinoma of bronchus.

Our patient was an old man, with sudden onset of palmoplantar keratoderma which did not respond to treatment with keratolytics, who was later detected to have internal malignancy. Treatment of the underlying malignancy with chemotherapy lead to the resolution of cutaneous symptoms. This case is being presented to highlight the fact that acquired palmoplantar keratodermas not responding to treatment presenting in the elderly, should repeatedly be screened for underlying malignancy.

\section{REFERENCES:}

1. Kelsell DP, Leigh IM. Inherited Keratodermas Of Palms and Soles. In: Wolff K, Goldsmith LA, et al. Fitzpatric's Dermatology In General Medicine. $7^{\text {th }}$ ed. New York: McGraw-Hill; 2008. P. 424.

2. Zemtsov A, Veitschegger M. Keratodermas. Int J Dermatol 1993 July; 32 (7): 493-498.

3. Lucker GPH, Van de Kerkhof PCM, Steiljen PM. The hereditary palmoplantar keratoses: an updated review and classification. Br J Dermatol 1994; 131: 1-14.

4. Ratnavel RC, Griffiths WAD. The inherited palmoplantar keratodermas. Br J Dermatol 1997 Oct; 137 (4): 485-90. 


\section{CASE REPORT}

5. Patel S, Zirwas M, English JC 3rd. Acquired palmoplantar keratoderma. Am J Clin Dermatol. 2007; 8 (1): 1-11.

6. Howel-Evans W, McConnell RB, Clarke CA, et al. Carcinoma of the oesophagus with keratosis palmaris et plantaris (tylosis): a study of two families. Q J Med 1958; 27:413-29.

\section{AUTHORS:}

1. T. V. Anoop

2. K. Radhakrishnan

3. S. Ajayakumar

4. S. Rajiv

5. M. Revathy

\section{PARTICULARS OF CONTRIBUTORS:}

1. Associate Professor, Department of Dermatology, Pariyaram Medical College.

2. Senior Lecturer, Department of Dermatology, Pariyaram Medical College.

3. Assistant Professor Department of Dermatology, Pariyaram Medical College.

4. Professor, Department of Dermatology, Pariyaram Medical College.
5. Resident, Department of Dermatology, Pariyaram Medical College.

\section{NAME ADDRESS EMAIL ID OF THE} CORRESPONDING AUTHOR:

\section{Dr. Anoop T. V,}

B 2 Quarters, F3,

Pariyaram Medical College,

Kannur-670503, Kerala.

Email: anooptvanoop@gmail.com

Date of Submission: 16/07/2014.

Date of Peer Review: 17/07/2014.

Date of Acceptance: 28/07/2014.

Date of Publishing: 02/08/2014. 